\title{
Cerebrospinal fluid flow dynamics study in Chiari I malformation: implications for syrinx formation
}

\author{
Giampietro Pinna, M.D., Franco Alessandrini, M.D., Alex Alfieri, M.D., \\ Marcella Rossi, M.D., AND Albino BRicolo, M.D. \\ Department of Neurosurgery and Service of Neuroradiology, University Hospital, Verona, Italy
}

\begin{abstract}
Cerebrospinal fluid (CSF) flow abnormalities are known to be present in Chiari I malformation and to underlie the origin and progression of associated syringomyelia. The incidence of syrinx formation, however, is variable for unknown reasons. The aim of this study was to investigate whether differences in CSF flow dynamics in patients with Chiari I malformation may account for the different clinical and radiological presentation.

Presurgical and postsurgical phase-contrast magnetic resonance imaging investigations were prospectively conducted in 47 adult patients with symptomatic Chiari I malformation. Patients were divided into two groups according to the presence (32 cases) or absence (15 cases) of syrinx. Cerebrospinal fluid flow patterns were evaluated at four regions of interest: prebulbar cistern, foramen magnum, and the ventral and dorsal spinal subarachnoid spaces at the C-5 level. A temporal analysis of CSF flow waveforms was performed with measurement of cranial- and caudal-directed flow durations. All patients underwent a craniocervical decompressive procedure. Preoperatively, a prolonged caudal-directed (systolic) flow pattern was observed in patients with syringomyelia, as compared with normal control values obtained in 15 healthy volunteers. Conversely, a decreased systolic duration was observed in Chiari I patients who had malformation without syrinx. These trends were not statistically significant because of the considerable degree of overlap with the control values recorded in both groups. Additional comparison of the observed preoperative values obtained in patients with and those without syringomyelia indicated that the difference in systolic flow duration was significant at the ventral spinal subarachnoid space level $(p=0.003)$ and remarkable at the other levels, although not reaching statistical significance. Cerebrospinal fluid flow was minimal or absent at the foramen magnum (dorsal aspect) due to tonsillar herniation, precluding reliable quantitative measurement at this level. There was no evidence of communication between the fourth ventricle and syrinx in any case. Postoperatively, unobstructed CSF flow was recorded across the enlarged foramen magnum and into the artificial cisterna magna in all patients. A gradual restoration of near-normal flow patterns was observed in both groups. Inside the syrinx, fluid motion gradually tapered, no longer being detectable in 12 patients $(37.5 \%) 1$ year postsurgery.

In patients with Chiari I malformation and associated syringomyelia different CSF flow patterns were demonstrated as compared with patients in whom syrinx was absent. Analysis of this study's findings supports the hypothesis that in Chiari I malformation an elongated systolic flow may prolong the condition of increased spinal subarachnoid pressure caused by the junctional obstruction, thus favoring CSF penetration into the spinal cord. It may be also proposed that a shortened systolic flow may be insufficient to maintain a hypertensive condition for enough time to induce syrinx formation.
\end{abstract}

\section{KEY WoRDS • Chiari I malformation • syringomyelia • cerebrospinal fluid • magnetic resonance imaging}

The innovative theory proposed by Oldfield and coworkers $^{27}$ in 1994 generated a reconsideration of the mechanisms underlying the origin and progression of syringomyelia associated with Chiari I malformation of the cerebellar tonsils. According to this theory, based on observation of CSF flow dynamics, the downward tonsillar displacement hinders the rapid bidirectional CSF passage

Abbreviations used in this paper: $\mathrm{AP}=$ anteroposterior; $\mathrm{CSF}=$ cerebrospinal fluid; MR = magnetic resonance; SSS = spinal subarachnoid space. across the foramen magnum, which normally occurs during each cardiac cycle in response to the pulsatile expansion and contraction of the brain. The partially isolated SSSs are therefore poorly compliant to the abrupt CSF volume changes induced by the downward tonsillar thrust that occurs at each systole. This generates increased pulsatile pressure waves that may force CSF to penetrate the spinal cord, whereby CSF acts on its surface and eventually causes a syrinx to form. The increased pulsatile pressure outside the spinal cord, which causes flow motion of the intraspinal fluid collection, may lead to syrinx progression. 
Validation of these hypotheses has recently been provided by the same investigative group,${ }^{17}$ yet other aspects of this complex disease remain unexplained. One unanswered question concerns the fact that a Chiari I malformation is not always associated with a syrinx, although it is conceivable that the same pathophysiological modifications are in play in every patient harboring this malformation. Although information regarding CSF flow abnormalities in Chiari-malformation-related syringomyelia is accruing, 2,5,10,17,34 little is known about CSF alterations in Chiari I malformation in the absence of syrinx. ${ }^{2,37}$ To the best of our knowledge, this issue has not been specifically addressed to date.

The present study was primarily designed to investigate whether differences of CSF flow dynamics exist among patients with Chiari I malformation and whether such differences may account for the variability of syrinx formation in these patients. Additional objectives were to assess the modification of CSF flow dynamics after decompressive surgery of the craniocervical junction and to evaluate the efficacy of this procedure in relieving clinical and radiologically documented alterations of this disease.

\section{CLINICAL MATERIAL AND METHODS}

\section{Patient Population}

From January 1994 to December 199747 adult patients with symptomatic Chiari I malformation underwent dynamic MR imaging investigation prior to surgical treatment. The patients were divided into two groups according to the presence (Group I; 32 patients) or absence (Group II; 15 patients) of a syrinx. In Group I there were 16 men and 16 women (mean age $37.5 \pm 14.1$ years, range 20-62 years). In Group II there were four men and 11 women (mean age $45.7 \pm 11.5$ years, range $27-62$ years). The mean age of the entire series was $39.7 \pm 13.7$ years. Any patient with associated relevant skull base anomalies was not included in this series.

Fifteen normal adult volunteers (Group III; mean age $36.4 \pm 9.1$ years, range $22-54$ years) underwent the same radiological investigation. Informed consent was obtained from each patient and from each healthy subject.

\section{Radiological Evaluation}

Magnetic resonance images of the cervicothoracic spine and of the posterior fossa were obtained on a 1.0 tesla scanner (Siemens, Magnetom Impact, Erlangen, Germany). In all patients prior to surgery and also in normal volunteers, AP diameters of the subarachnoid spaces at the foramen magnum were measured on midsagittal $\mathrm{T}_{1}$ weighted MR images, either ventrally to the brainstem or dorsally to the brainstem or herniated tonsils. In patients in Group I the maximum AP diameter of the syrinx and those of the ventral and dorsal SSSs were also measured. The same measurements were repeated in controls after surgery.

Dynamic MR imaging was used to evaluate the CSF flow across the foramen magnum, in the SSSs and inside the syrinx (when present). The cardiac-gated MR image acquisition sequence was triggered by the $R$ wave of the electrocardiogram. Phase-contrast imaging was conducted using a gradient echo fast low-angle shot two-dimensional sequence. Imaging parameters were as follows: repetition time $50 \mathrm{msec}$; echo time $13 \mathrm{msec}$; flip angle $20^{\circ}$; section thickness $4 \mathrm{~mm}$; field of view $230 \times 230$; and acquisition matrix $192 \times 256$, two acquisitions. Ten to 14 images of the same slice were obtained depending on the heart rate of the patient/volunteer. Sagittal images were arranged in a loop sequence (cine mode), allowing a dynamic view of the CSF flow. By convention caudal-directed flow is defined as systolic and cranial-directed flow as diastolic. We examined CSF flow patterns on axial slices at four regions of interests: one placed slightly above the foramen magnum, in the cistern ventral to the medulla oblongata (prebulbar); one placed at the foramen magnum, dorsal aspect; and two placed below the foramen magnum, in the ventral and in the dorsal SSS at the C-5 level. Cerebrospinal fluid flow was also evaluated at the fourth ventricle/aqueduct level and, when present, inside the syrinx. Amplitude (velocity) parameters were not available for analysis. A temporal analysis of CSF flow waveforms involved determining the intervals from the $\mathrm{R}$ wave to the onset of CSF systole and diastole, as well as measuring the duration of CSF systole and diastole. Because these durations are complementary, only the duration of CSF systole will be reported. These data are expressed as percentage of the $\mathrm{R}-\mathrm{R}$ interval.

\section{Clinical Evaluation}

In Group I, 21 patients (65.6\%) presented with signs and symptoms of myelopathy due to the spinal cord cavitation. Clinical disturbances included sensory loss, dysesthetic pain, limb weakness, spasticity, muscle atrophy, and sphincteric disturbances. Eight patients $(25 \%)$ presented with clinical disturbances related to both the syrinx and brainstem compression; the latter included cranial nerve impairment, vertigo, ataxia (balance), limb weakness, and spasticity. In three patients (9.4\%) complaints were unrelated to the syrinx: two patients had signs and symptoms of brainstem compression, and one presented with trigeminal neuralgia. The mean duration of symptoms was $56.4 \pm 46.6$ months (range $1-180$ months) in this group.

In Group II (without associated syringomyelia) 12 patients $(80 \%)$ presented with signs and symptoms related to brainstem compression. Three patients $(20 \%)$ presented with a distressing exertional headache, although results of the neurological examination were unremarkable. The mean duration of preoperative disturbances was $60.1 \pm$ 61.9 months (range 12-228 months) in this group.

A thorough description of the clinical disturbances affecting patients is beyond the scope of this report. Postoperative results were evaluated maintaining the aforementioned subdivision of clinical complaints: related to syrinx, related to brainstem compression, or unrelated. For each grouping, signs and symptoms were reported as "disappeared," "improved," "unchanged," or "worse."

\section{Surgical Treatment}

The same surgical procedure was undertaken in all cases. Patients were placed in the semisitting position, and a suboccipital craniectomy was performed in which the posterior arch of C-1 (and C-2, depending on the extent of tonsillar descent) was removed. An intraarachnoid 
TABLE 1

Magnetic resonance findings in patients with Chiari I malformation and in healthy volunteers*

\begin{tabular}{|c|c|c|c|c|c|c|c|c|}
\hline & \multicolumn{3}{|c|}{ Group I (32 patients) } & \multicolumn{3}{|c|}{ Group II (15 patients) } & \multicolumn{2}{|c|}{ Group III (15 volunteers) } \\
\hline & Preop & $\begin{array}{c}\text { Postop } \\
(1 \mathrm{yr})\end{array}$ & $\mathrm{p}$ Value & Preop & $\begin{array}{c}\text { Postop } \\
(1 \mathrm{yr})\end{array}$ & $\mathrm{p}$-Value & $\begin{array}{c}\text { Measure- } \\
\text { ment }\end{array}$ & $\mathrm{p}$ Value \\
\hline \multicolumn{9}{|l|}{ foramen magnum } \\
\hline ventral AP diam (mm) & $1.5 \pm 0.7$ & $3.0 \pm 1.2$ & $<0.0001^{*}$ & $1.4 \pm 0.4$ & $3.4 \pm 1.5$ & $0.005 *$ & $7.1 \pm 1.9$ & $<0.0001 \dagger$ \\
\hline dorsal AP diam (mm) & 0 & $11.7 \pm 2.6$ & $<0.0001^{*}$ & 0 & $10.9 \pm 6.3$ & $0.002 *$ & $6.1 \pm 2.7$ & $<0.0001 \div$ \\
\hline syrinx (max AP diam mm) & $6.5 \pm 2.7$ & $1.7 \pm 1.9$ & $<0.0001^{*}$ & & & & & \\
\hline \multicolumn{9}{|l|}{ SSS } \\
\hline ventral AP diameter $(\mathrm{mm})$ & $2.4 \pm 1.3$ & $4.4 \pm 2.4$ & $0.008 *$ & & & & & \\
\hline dorsal AP diameter (mm) & $1.1 \pm 1.0$ & $2.7 \pm 1.1$ & $<0.0001^{*}$ & & & & & \\
\hline
\end{tabular}

approach was performed to achieve tonsillar shrinkage, lysis of arachnoidal adhesions, and exploration of Magendie's foramen to remove any possible obstacle to CSF outflow from the fourth ventricle. No attempts were made to plug the obex, to insert a stent, or to drain the syrinx, if present. An artificial cisterna magna was recreated by dural grafting.

\section{Postoperative Evaluation}

Standard and dynamic MR control images were scheduled to be obtained at 3 months and 1 year after surgery. Postoperative clinical status was also assessed. Long-term evaluation of results of the surgical procedure, obtained by a clinical reassessment, was conducted in the summer and fall of 1999.

\section{STATISTICAL ANALYSIS}

Statistical analyses were performed using the SPSS for Windows software (version 9.0; SPSS, Inc., Chicago, IL). Values are expressed as the mean \pm standard deviation. The paired two-tailed t-test was used to compare data obtained in patients before and after surgery. Comparison of the values obtained in patients of different groups, both before surgical treatment and at follow-up examinations, or with those obtained in normal volunteers was performed using the unpaired two-tailed t-test. Any value of $\mathrm{p}<0.05$ was considered to be statistically significant.

\section{RESULTS}

\section{Radiological Evaluation}

Preoperative. Preoperative measurement of the width of the SSSs at the foramen magnum in Group I and II patients demonstrated a severe narrowing as compared with healthy volunteers (Table 1). Mean AP diameters measured ventral to the medulla oblongata were $1.5 \pm 0.7$ $\mathrm{mm}$ in Group I and $1.4 \pm 0.4 \mathrm{~mm}$ in Group II (Group III $7.1 \pm 1.9 \mathrm{~mm} ; \mathrm{p}<0.0001)$. Dorsal CSF spaces were totally occluded by the herniated tonsils in patients of both groups (diameter $0 \mathrm{~mm}$; controls $6.1 \pm 2.7 \mathrm{~mm}$; p < 0.0001). Phase-contrast MR imaging confirmed the func- tional occlusion at this level with absence of fluid passage in the vast majority of patients. In two cases only, a very short-lasting, caudal-directed flow was detectable. Diastolic flow across the foramen magnum was not detected. Cine MR imaging demonstrated the abrupt downward motion of the impacted cerebellar tonsils at each systole. Dynamic MR imaging also demonstrated the absence of a functional communication (fluid passage) between the fourth ventricle and the intraspinal cavity in all patients with syringomyelia (Group I). It is worth noting that in two cases sagittal $\mathrm{T}_{1}$-weighted MR images were suggestive of the presence of such communication.

Temporal analysis of CSF systolic flow duration was possible in the majority of patients (44 [93.6\%] of 47). In three cases (two in Group I and one in Group II) the poor quality of preoperative phase-contrast MR images prevented us from obtaining reliable CSF flow measurements, and these cases were not considered for quantitative analysis. In both groups, a considerable degree of overlap with CSF flow values recorded in normal subjects was observed. However, a slight increase of systolic flow duration was observed in Group I patients as compared with controls (Table 2). Mean durations of CSF systole were recorded as $57.5 \pm 14.8 \%, 59.2 \pm 14.5 \%$, and $52.8 \pm$ $15.6 \%$ (percentages of $\mathrm{R}-\mathrm{R}$ interval) at the prebulbar cistern, ventral and dorsal SSS levels, respectively (controls $55.4 \pm 12.8,53.2 \pm 13.6,44.4 \pm 13.8$ ). Cerebrospinal fluid flow values in the foramen magnum were not measurable (controls $46.7 \pm 14.9$ ). On the other hand, a marked decrease of systolic flow duration was recorded in Group II patients, as compared with the normal values obtained in volunteers (prebulbar cistern $48.5 \pm 12.1$; ventral SSS $44.7 \pm 13.7$; and dorsal SSS $44.0 \pm 15.9$ ). These trends were not statistically significant with respect to normal flow values. However, when comparing the two groups of patients, differences approached statistical significance $(\mathrm{p}$ $=0.057$ ) at the prebulbar cistern level, were highly significant $(\mathrm{p}=0.003)$ at ventral SSS level, and not significant $(\mathrm{p}=0.11)$ at the dorsal SSS level (Table 2).

Fluid motion within the syrinx was detected preoperatively in all Group I patients. Cine MR imaging frequently revealed turbulent patterns, most often observed in patients with larger cavities (13 [40.6\%] of 32). Changes in flow direction inside the syrinx did not always parallel those observed in subarachnoid spaces outside the spinal 
TABLE 2

Duration of CSF systole expressed as percentage of the $R-R$ interval

\begin{tabular}{lcccc}
\hline \hline & $\begin{array}{c}\text { Group I } \\
(30 \text { patients })\end{array}$ & $\begin{array}{c}\text { Group II } \\
(14 \text { patients })\end{array}$ & $\begin{array}{c}\text { Group III } \\
(15 \text { volunteers })\end{array}$ & $\begin{array}{c}\mathrm{p} \\
\text { Value* }\end{array}$ \\
\hline prebulbar cistern & $57.5 \pm 14.8$ & $48.5 \pm 12.1$ & $55.4 \pm 12.8$ & $0.14 \dagger$ \\
& & & & $0.65 \ddagger$ \\
ventral SSS & $59.2 \pm 14.5$ & $44.7 \pm 13.7$ & $53.2 \pm 13.6$ & $\begin{array}{l}0.057 \S \\
0.10 \dagger \\
\end{array}$ \\
& & & & $0.19 \ddagger$ \\
dorsal SSS & $52.8 \pm 15.6$ & $44 \pm 15.9$ & $44.4 \pm 13.8$ & $0.003 \S$ \\
& & & & $0.09 \ddagger$ \\
& & & & $0.11 \S$ \\
\hline
\end{tabular}

* Unpaired two-tailed t-test.

$\dagger$ Comparison of Group I preoperative values with Group III values. \$ Comparison of Group II preoperative values with Group III values.

$\S$ Comparison of group I and II preoperative values.

cord. Uncoupled flow pattern variations were observed in $21(65.6 \%)$ of 32 patients.

Postoperative. All patients were available for follow-up controls. For the sake of simplicity, only data from the final MR examination (1 year postsurgery) are reported.

Surgical decompression of the foramen magnum expanded both ventral and dorsal CSF spaces at this level. In Group I mean AP diameters expanded from $1.5 \pm 0.7 \mathrm{~mm}$ preoperatively to $3.0 \pm 1.2 \mathrm{~mm}$ postoperatively (ventral, $\mathrm{p}$ $<0.0001$ ) and from 0 to $11.7 \pm 2.6 \mathrm{~mm}$ (dorsal, $\mathrm{p}<$ 0.0001). In Group II, CSF spaces at the foramen magnum expanded from $1.4 \pm 0.4 \mathrm{~mm}$ to $3.4 \pm 1.5 \mathrm{~mm}$ (ventral, $\mathrm{p}$ $=0.005$ ) and from 0 to $10.9 \pm 6.3 \mathrm{~mm}$ (dorsal, $\mathrm{p}=0.002$ ). In both groups of patients a well-recreated cisterna magna was observed on standard MR imaging.

A progressive decrease of the syrinx size was observed in Group I patients after undergoing craniocervical decompressive surgery (Table 1 and Figs. 1 and 2). Mean diameters decreased from $6.5 \pm 2.7 \mathrm{~mm}$ to $1.7 \pm 1.9 \mathrm{~mm} 1$ year postoperatively $(\mathrm{p}<0.0001)$. A parallel enlargement of the SSSs was also measured (from $2.4 \pm 1.3 \mathrm{~mm}$ to $4.4 \pm 2.4 \mathrm{~mm}$ [ventral spaces] $\mathrm{p}=0.008$; and from $1.1 \pm$ $1.0 \mathrm{~mm}$ to $2.7 \pm 1.1 \mathrm{~mm}$ [dorsal spaces] $\mathrm{p}<0.0001$ ). One year after surgery, the syrinx disappeared in 12 cases $(37.5 \%)$, was reduced in 18 cases $(56.2 \%)$, and was unchanged in two cases $(6.3 \%)$.

Phase-contrast MR imaging demonstrated an unobstructed CSF flow through the enlarged foramen magnum and into the artificial cisterna. Results of quantitative temporal analysis 1-year postoperatively demonstrated that flow patterns approached normal values in both groups of patients (Table 3). It is worth noting that, whereas the difference between pre- and postoperative values was not statistically significant for Group I patients (Table 3), the postsurgical increase of CSF flow durations was highly significant at the prebulbar cistern and ventral SSS levels $(\mathrm{p}=0.03$ and $\mathrm{p}=0.007$, respectively) in Group II patients.

In addition to the normalization of CSF flow patterns outside the spinal cord, a gradual reduction of fluid motion inside the syrinx was observed in Group I patients. The decrease in intraspinal flow paralleled the size reduction of the syrinx. Nevertheless, residual syrinx fluid flow was still present in 20 patients $(62.5 \%) 1$ year after sur-

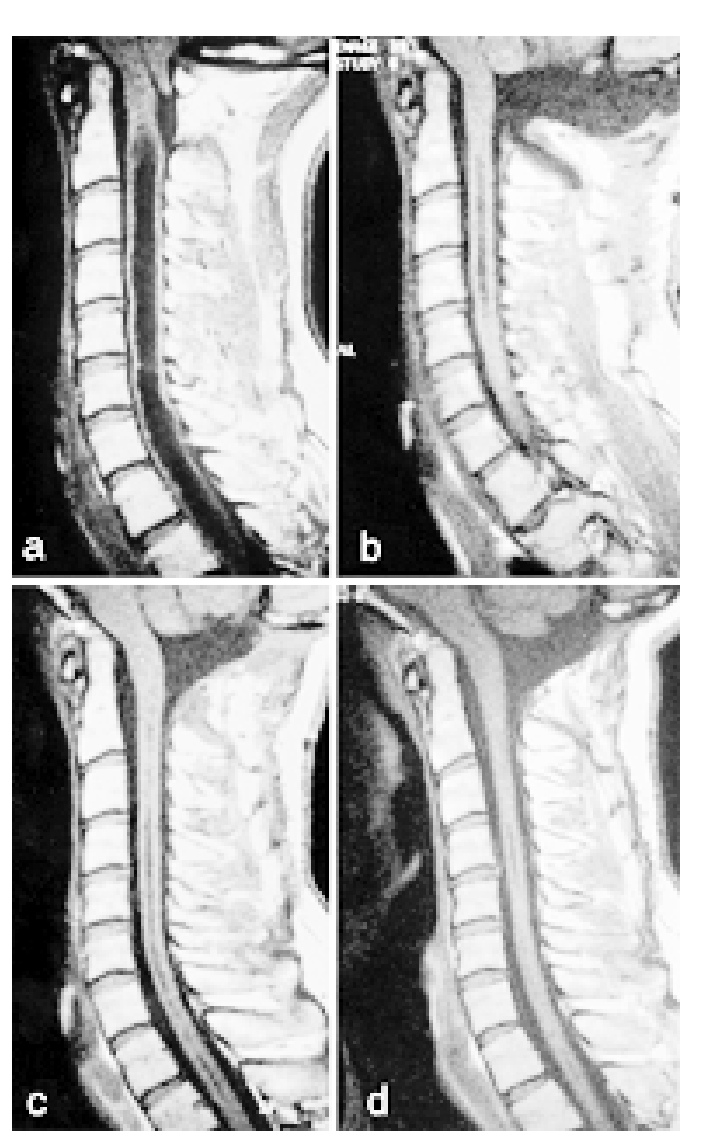

Fig. 1. Sagittal $\mathrm{T}_{1}$-weighted MR images. Chiari I malformation is demonstrated with tonsillar descent and an associated cervicothoracic syrinx (a). After surgery, a large artificial cisterna magna is evident. Progressive syrinx reduction was observed at 1 month (b) and at 3 months (c). A tiny residual of the cavity is visible 1 year after surgery $(d)$.

gery. These fluid flow values, however, were not detectable for the entire duration of the cardiac cycle, as they were most evident in early systole. A complete disappearance of fluid motion into the spinal cord was observed in 12 patients $(37.5 \%)$, on the final 1-year MR control images.

\section{Clinical Evaluation}

Postoperative clinical status was assessed at 3 months and 1 year. All patients included in this series were also available for long-term follow-up control examination. The mean follow-up duration was $45.9 \pm 14.0$ months (range 22-65 months). The 1-year postoperative results are summarized in Table 4.

In Group I patients, syrinx-related signs and symptoms were completely resolved in seven patients $(24.1 \%)$, improved in $19(65.6 \%)$, and were stable in three $(10.3 \%)$. Clinical disturbances related to brainstem compression, which was present preoperatively in 10 patients with syringomyelia, disappeared after surgery in eight cases $(80 \%)$ and were improved in two $(20 \%)$. No postoperative worsening of clinical signs or symptoms was recorded. The patient who presented with trigeminal neuralgia experienced a complete remission of his symptomatology. In 


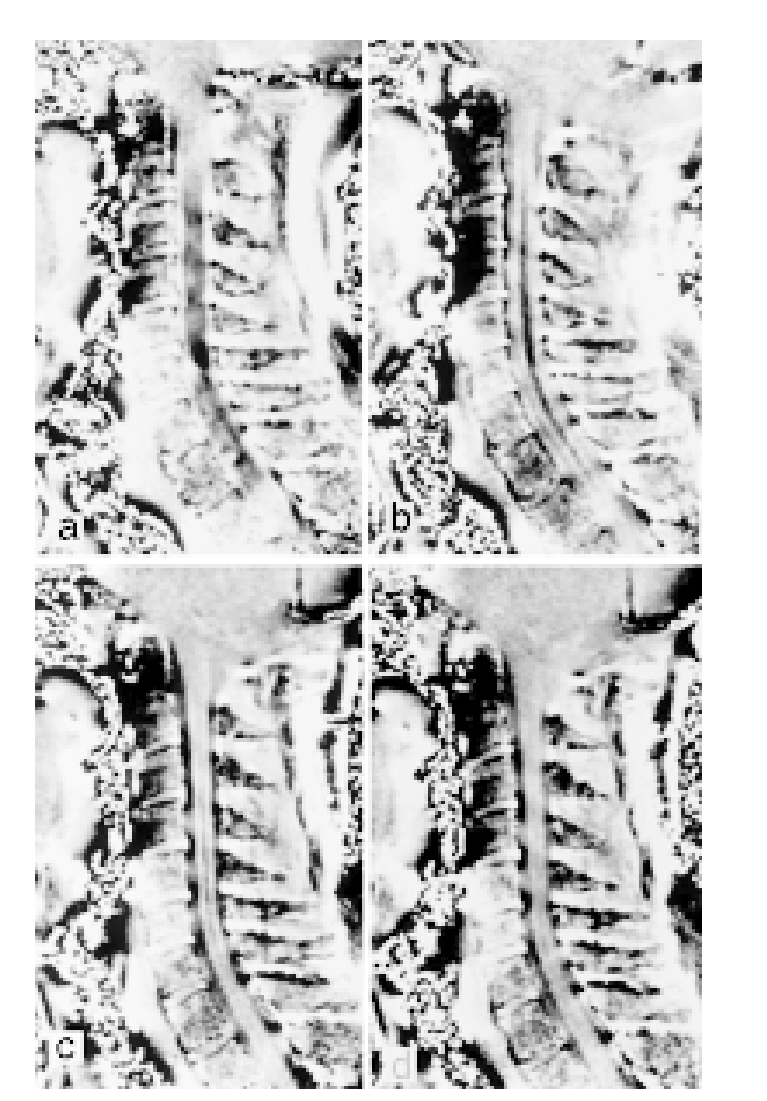

Fig. 2. Phase contrast MR images. Preoperative image obtained, $200 \mathrm{msec}$ after the $\mathrm{R}$ wave (a): no flow is present at the craniospinal junction and is scarcely visible in the SSSs; systolic flow (low signal) is evident inside the syrinx. One month (b) and 3 months (c) after surgery systolic flow is well demonstrated in the enlarged spinal spaces, and in the artificial cisterna magna, flow motion is still evident into the reduced syrinx, which become hardly recognizable 1 year after surgery (d).

summary, assuming that favorable results are indicated by the disappearance or improvement of preoperative clinical disturbances, the rate of improvement was $89.7 \%$ in syrinx-related disturbances (26 patients out of 29 with a symptomatic syrinx) and $100 \%$ for brainstem-related disturbances in Group I.

In Group II, of the 12 patients presenting with signs and symptoms of brainstem compression, postoperative resolution was observed in nine patients (75\%), improvement in one $(8.3 \%)$, and no change in two $(16.7 \%)$. In all three patients suffering preoperatively from severe exertional headache, complete symptom relief was attained after surgery. The rate of improvement in this group was $86.7 \%$ (13 of 15 patients with favorable results). Long-term follow-up evaluations showed a substantial stabilization of the results achieved after 1 year.

\section{Surgical Procedure}

The surgical procedure was well tolerated in all patients. Surgery-related complications included one case of aseptic meningitis and one case of acute hydrocephalus due to a postoperative extradural CSF collection. In both cases, wound revision was followed by an uneventful course, and the patients experienced a favorable outcome. Three patients experienced a postoperative persistent fever that resolved with brief period in which steroid drugs were administered. In our opinion, the latter side effects, and possibly also the aseptic meningitis, were related to the use of heterologous dural grafting. We overcame this problem by using autologous material.

\section{DISCUSSION}

In recent years, motion-sensitive MR imaging techniques have allowed investigations of CSF flow dynamics, both in normal and pathological conditions. ${ }^{7,11,12,15,24,}$ 25,28,31,32 In a noninvasive manner, these techniques have provided us with invaluable information on a closed system such as the CSF circulation. Chiari I malformation, a condition known to be associated with CSF flow abnormalities, has been the subject of a number of these studies, both before and after decompressive surgery. $2,4,5,10,27,34,37$ This condition represents, in fact, an interesting model of acquired CSF flow derangement. Moreover, because of its frequent association with syringomyelia investigators have focused attention on the unsettled question of the origin of the fluid collection within the spinal cord. Based on dynamic MR imaging findings and direct intraoperative ultrasonography recordings, in 1994 Oldfield, et al., ${ }^{27}$ formulated a novel theory to explain the progression of syringomyelia, which confuted those previously proposed by Gardner and Angel ${ }^{14}$ and Williams ${ }^{36}$ that had been widely accepted until that time. This theory received experimental confirmation by the prospective study undertaken by Heiss, et al., ${ }^{17}$ whose results were consistent with the fact that cerebellar tonsillar displacement, occurring in Chiari I malformation, produces a functional CSF blockage at the foramen magnum. In this condition, brain expansion during cardiac systole induces an abrupt downward thrust of the herniated tonsils into the almost completely excluded

TABLE 3

Preoperative and postoperative duration of CSF systole in patients with Chiari I malformation

\begin{tabular}{|c|c|c|c|c|c|c|}
\hline & \multicolumn{3}{|c|}{ Group I } & \multicolumn{3}{|c|}{ Group II } \\
\hline & Preop & Postop & p Value* & Preop & Postop & p Value* \\
\hline prebulbar cistern & $57.5 \pm 14.8$ & $54.7 \pm 8.1$ & 0.35 & $48.5 \pm 12.0$ & $55.7 \pm 9.3$ & 0.03 \\
\hline foramen magnum & 0 & $51.0 \pm 12.1$ & NA & 0 & $49.7 \pm 10.6$ & NA \\
\hline ventral SSS & $59.2 \pm 14.5$ & $54.2 \pm 12.7$ & 0.13 & $44.7 \pm 73.7$ & $54.6 \pm 8.8$ & 0.007 \\
\hline dorsal SSS & $52.8 \pm 15.6$ & $50.4 \pm 11.1$ & 0.43 & $44.0 \pm 15.9$ & $50.5 \pm 9.0$ & 0.10 \\
\hline
\end{tabular}

* Significance was established using the paired two-tailed t-test. Abbreviation: NA $=$ not applicable. 
TABLE 4

Clinical assessment 1 year after decompressive surgery

\begin{tabular}{|c|c|c|c|c|c|c|c|c|c|c|}
\hline \multirow[b]{2}{*}{$\begin{array}{c}\text { Related } \\
\text { Signs \& Symptoms }\end{array}$} & \multicolumn{5}{|c|}{ Group I } & \multicolumn{5}{|c|}{ Group II } \\
\hline & $\begin{array}{l}\text { Disap- } \\
\text { peared }\end{array}$ & $\begin{array}{c}\text { Im- } \\
\text { proved }\end{array}$ & $\begin{array}{c}\text { Un- } \\
\text { changed }\end{array}$ & Worse & Total & $\begin{array}{l}\text { Disap- } \\
\text { peared }\end{array}$ & $\begin{array}{c}\text { Im- } \\
\text { proved }\end{array}$ & $\begin{array}{c}\text { Un- } \\
\text { changed }\end{array}$ & Worse & Total \\
\hline syrinx & 5 & 14 & 2 & & 21 & & & & & \\
\hline syrinx \& & $2 *$ & $5^{*}$ & $1 *$ & & 8 & & & & & \\
\hline brainstem compression $\div$ & $6 \div$ & $2 \dagger$ & & & & & & & & \\
\hline brainstem compression & 2 & & & & 2 & 9 & 1 & 2 & & 12 \\
\hline unrelated & 1 & & & & 1 & 3 & & & & 3 \\
\hline total & 16 & 21 & 3 & & 32 & 12 & 1 & 2 & & 15 \\
\hline
\end{tabular}

* Related to the presence of a syrinx.

$\dagger$ Related to the presence of brainstem compression.

\$ Eight patients presented signs and symptoms related to both syrinx and brainstem compression.

SSSs. These volume changes are transmitted to the walls of these spaces, including the spinal cord surface, through increased pulsatile pressure waves. This causes an increase in syrinx fluid pressure which, in turn, propels the fluid downward to cause syrinx progression. Although clear-cut demonstration in humans has not been attained, the condition of increased spinal subarachnoid pressure would force the CSF into the spinal cord. Aboulker ${ }^{1}$ has proposed that CSF penetration into the spinal parenchyma from outside may be a possible mechanism for syrinx formation. He supposed that the increased CSF volume, occurring in conditions of spinal CSF block at the craniospinal junction, could accumulate into the spinal cord to induce edema, cavitation, and syrinx formation. The dorsal rootlets entry zone was the supposed pathway for CSF penetration. Ball and Dayan ${ }^{3}$ are credited with proposing the existence of a similar mechanism for the first time, suggesting that CSF penetrates through the perivascular (Virchow-Robin) spaces. Evidence exists that these spaces provide a route of fluid exchange between the spinal extracellular and subarachnoid spaces. ${ }^{29}$ Also, these spaces were found to be dilated in patients with syringomyelia ${ }^{3,16}$ and to be the route of penetration of labeled tracers or other water-soluble media into the syrinx shortly after intrathecal injection. ${ }^{6,8,13,18,20,22,23,30}$ In an animal model of noncommunicating syringomyelia, Stoodley et al. ${ }^{33}$ have shown that horseradish peroxidase penetrates into the spinal cord and the dilated central canal (a condition mimicking a syrinx) via the perivascular spaces. This occurrence may possibly be induced by an increased pulse pressure rostral to the experimentally induced CSF block.

Taken together, clinical and experimental evidence suggest that the mechanism of syrinx formation is independent from the existence of a communication between the fourth ventricle and the spinal cavity. Analysis of our study results provides additional support for this concept. A fluid passage from the fourth ventricle into the syrinx was not observed in any of the 32 patients with syringomyelia, even in those in whom neuroimaging revealed evidence of such communication. Cine MR imaging data suggest that the downward displacement of the cerebellar tonsils (and brainstem) at each systole may exert a "squeezing" effect on the bulbomedullary junction, possibly occluding any channel at this level. It may be argued from these findings that a direct connection between fourth ventricle and syr- inx, if it exists, is not functionally active and plays no role in the formation and progression of the syrinx.

Although the absence of intraspinal fluid collection in Chiari I malformation is likewise intriguing, it has received far less consideration. With the assumption that the theory proposed by Oldfield, et al., ${ }^{27}$ is true - and the experimental evidence supports this theory-it may be hypothesized that the same, or very similar, modifications of CSF flow dynamics occur in every patient with Chiari I malformation.

To date, no published report specifically addresses the reasons for differences in clinical and radiological presentation in Chiari I malformation. Previously, investigators studied CSF flow dynamics in Chiari I malformation patients, considering those with and without syringomyelia as a single group. ${ }^{2,4}$ More recent studies have been conducted only in patients with syringomyelia., ${ }^{5,17,27,34}$ In the largest series of Chiari I malformation patients recently reported by Milhorat, et al., ${ }^{21}$ a number of patients were included both with and without syringomyelia, who underwent dynamic MR studies. Cerebrospinal fluid flow velocity values measured in the foramen magnum level were found to be both increased and decreased in different groups, but no additional specification was offered. In most of the published studies, investigations were conducted of CSF flow velocity abnormalities, sometimes with conflicting results. ${ }^{5,17,27,34,37}$

In the present study designed to investigate CSF flow dynamics in a noninvasive way, we differentiated the two clinical presentations, and the results indicate that differences exist between patients with or those without associated syringomyelia. Because quantification of CSF flow velocities was not available by using our MR imager, we attempted a slightly different approach by analyzing CSF flow duration. Previously reported data related to this approach have been sparse. ${ }^{2,4}$ Analysis of our results demonstrates that, before surgery, patients without syrinx have a shorter systolic flow duration as compared with patients with syrinx. This difference is highly significant $(\mathrm{p}=$ 0.003 ) when measured in the ventral SSS. However, markedly shorter systolic flow durations were also recorded in the prebulbar cistern and in dorsal SSS. By comparing preoperative data of both treatment groups with that obtained in the control group, it is interesting to note that in Group I patients (with syringomyelia) an increased sys- 
tolic CSF flow duration was observed in all regions in which flow velocity was measured, whereas in Group II patients (without syringomeylia) a shorter systolic duration than normal subjects was demonstrated. These results are consistent with those reported by other investigators. ${ }^{2,4}$ Bhadelia, et al., ${ }^{4}$ have also reported a decreased duration of CSF systole in the ventral and dorsal spinal spaces, immediately below the foramen magnum, whereas in the prebulbar cistern an increased CSF systolic duration was recorded, although with a high variability range. Similar findings were also reported by Armonda, et al. ${ }^{2}$ It is worth noting, however, that in both reported series the authors did not differentiate between patients with or without those an associated syrinx but instead considered all patients as one group; in addition, the series included pediatric patients, although it is known that CSF flow dynamics are age related. ${ }^{26,35}$

Analysis of measurements obtained postoperatively demonstrated the restoration of near-normal flow parameters in both patient groups. Unobstructed CSF flow across the enlarged foramen magnum and progressive decrease of syrinx flow confirm that a craniocervical decompressive procedure can effectively correct this malformation. Cerebrospinal fluid flow dynamics data obtained in this study are consistent with the fact that removal of the junctional block reestablishes the normal communication between cranial and spinal compartments. The resolution of the condition of increased spinal subarachnoid pressure interrupts the mechanisms of syrinx maintenance, leading to a progressive reduction in cavity size and eventually to its collapse. It is of interest to note that the rate of syrinx disappearance in this series was $37.5 \%$ (12 of 32 patients). In the majority of cases a residual syrinx was still visible on follow-up MR control images. These data were not surprising and probably reflect the atrophic state of the spinal cord, induced by the increased preoperative syrinx pressure. This condition, however, does not necessarily correlate with clinical disturbances.

As reported by Heiss, et al., ${ }^{17}$ direct measurement of CSF flow values clearly indicates that the maximum increase in subarachnoid pressure at the cervical level occurs during the caudal-directed (systolic) flow, mostly in its early phase. Based on these data and on the present study findings, we propose that in patients harboringh a Chiari I malformation a syrinx may develop if the increased CSF pulsatile pressure is exerted on the spinal cord surface for a sufficient time. This means that an increased systolic CSF duration could prolong the hypertensive CSF condition exerted on the spinal cord surface over time, thus favoring fluit penetration into the spinal cord. On the other hand, it is conceivable that, because of reduced systolic flow durations, in patients not presenting with a syrinx the condition of increased CSF subarachnoid pressure may not endure long enough to induce syrinx formation.

It is reasonable to consider that other factors are involved in the pathogenesis of syringomyelia. The first is another time-dependent variable. Chiari I malformation is an acquired, not a congenital, disorder. However, it is impossible to estabilish exactly at which point the cerebellar tonsils' descent occurs in each patient and how long it takes, once present, to become symptomatic. It is theoretically possible that in patients without a syrinx, the period of time it takes malformation settlement to occur may be shorter, and a patient becomes symptomatic earlier because of a brainstem conflict with the clivus, on individual basis. This period could be not sufficiently long to induce syrinx formation. Another possibility is that CSF flow blockage is not always present at the foramen magnum. We should consider the tonsillar descent as a dynamic phenomenon (as cine MR imaging nicely displays) that is potentially reversible. Intermittent spontaneous relief of CSF block could temporarily resolve the hypertensive condition. The extent of tonsillary descent may not be considered crucial in this sense, as it has been demonstrated that there is no direct correlation between tonsillar herniation and clinical symptoms..$^{9,21}$

One more factor that could influence the penetration of CSF into the spinal cord is the compliance of the spinal cord itself to pressure modifications. This factor is also unpredictable, and there is no known method with which to determine its relevance in normal and pathological conditions.

Clinical results of this study also indicate that a craniocervical decompressive procedure adequately treats Chiari I malformation-related disturbances. Patients with signs and symptoms of brainstem compression were especially responsive to the posterior fossa enlargement, as were those with syrinx-related clinical disturbances. Although the results of this series are rewarding, it must be pointed out that improvement of syrinx-induced signs and symptoms of spinal cord dysfunction is not easily predictable. Clinical outcome depends on the degree of spinal cord damage induced by the syrinx.

Finally, some technical aspects of the surgical procedure deserve comment. An intraarachnoid approach is not generally recommended, ${ }^{17,27}$ as it is considered unwarranted and risky. We agree with the assumption that tonsillar shrinkage is probably not necessary to enlarge CSF spaces, and, according to the pathophysiological premises, we never attempted to plug the obex or to insert a shunt into the syrinx. Nevertheless, we would like to remark on the need for an intraarachnoid exploration. Recognition of arachnoidal adhesions or partial obstruction of Magendie's foramen is crucial to ensure a free CSF outflow from the fourth ventricle. These obstacles may be responsible for most of the cases in which craniocervical decompression failed because the procedure was limited to an osteodural decompression. ${ }^{19}$ In our experience the intraarachnoid approach is safe, yet expert and careful microsurgical dissections are required to accomplish this goal.

\section{CONCLUSIONS}

The results of this study indicate that in patients with Chiari I malformation presenting with an associated syrinx, patterns of CSF flow dynamics differ from those observed in patients without a syrinx. These findings support the hypothesis that in patients with Chiari I malformation an elongated systolic flow may prolong the condition of increased spinal subarachnoid pressure, caused by the junctional obstruction, thus encouraging CSF penetration into the spinal cord. On the other hand, a shortened systolic flow may be insufficient to mantain a hypertensive CSF condition for enough time to induce fluid accumulation into the spinal cord. 
The results of this study provide additional support to the concept that relief of CSF block obtained by performing a craniocervical decompressive procedure restores a physiological CSF flow condition.

\section{Acknowledgment}

The authors wish to thank Mrs. Vicky Praino for her invaluable assistance in editing the manuscript.

\section{References}

1. Aboulker J: La syringomyélie et les liquides intrarachidiens. Neurochirurgie 25 (Suppl 1):1-144,1979

2. Armonda RA, Citrin CM, Foley KT, et al: Quantitative cinemode magnetic resonance imaging of Chiari I malformations: an analysis of cerebrospinal fluid dynamics. Neurosurgery 35: 214-224, 1994

3. Ball MJ, Dayan AD: Pathogenesis of syringomyelia. Lancet 2: 799-801, 1972

4. Bhadelia RA, Bogdan AR, Wolpert SM, et al: Cerebrospinal fluid flow waveforms: analysis in patients with Chiari I malformation by means of gated phase-contrast MR imaging velocity measurements. Radiology 196:195-202, 1995

5. Brugières $\mathrm{P}$, Iffenecker $\mathrm{C}$, Hurth $\mathrm{M}$, et al: [Dynamic MRI in the evaluation of syringomyelic cysts.] Neurochirurgie 45 (Suppl 1):115-129, 1999 (Fr)

6. Dubois PJ, Drayer BP, Sage M, et al: Intramedullary penetrance of metrizamide in the dog spinal cord. AJNR 2:313-317, 1981

7. Edelman RR, Wedeen VJ, Davis KR, et al: Multiphasic MR imaging: a new method for direct imaging of pulsatile CSF flow. Radiology 161:779-783, 1986

8. Ellertsson AB, Greitz T: Myelocystographic and fluorescein studies to demonstrate communication between intramedullary cysts and the cerebrospinal fluid space. Acta Neurol Scand 45: 418-430, 1969

9. Elster AD, Chen MY: Chiari I malformations: clinical and radiological reappraisal. Radiology 183:347-353,1992

10. Enzmann DR: Imaging of syringomyelia, in Batzdorf U (ed): Syringomyelia: Current Concepts in Diagnosis and Treatment. Baltimore: Williams \& Wilkins, 1991, pp 116-139

11. Enzmann DR, Pelc NJ: Cerebrospinal fluid flow measured by phase-contrast cine MR. AJNR 14:1301-1310, 1993

12. Enzmann DR, Pelc NJ: Normal flow patterns of intracranial and spinal cerebrospinal fluid defined with phase-contrast cine MR imaging. Radiology 178:467-474, 1991

13. Forbes WSC, Isherwood I: Computed tomography in syringomyelia and the associated Arnold-Chiari type I malformation. Neuroradiology 15:73-78, 1978

14. Gardner WJ, Angel J: The mechanism of syringomyelia and its surgical correction. Clin Neurosurg 6:131-140, 1959

15. Greitz D, Wirestam R, Franck A, et al: Pulsatile brain movement and associated hydrodynamics studied by magnetic resonance phase imaging. The Monroe-Kellie doctrine revisited. Neuroradiology 34:370-380, 1992

16. Hassin GB: A contribution to histopathology and histogenesis of syringomyelia. Arch Neurol Psychiatry 3:130-146, 1920

17. Heiss JD, Patronas N, DeVroom HL, et al: Elucidating the pathophysiology of syringomyelia. J Neurosurg 91:553-562, 1999

18. Ikata T, Masaki K, Kashiwaguchi S: Clinical and experimental studies on permeability of tracers in normal spinal cord and syringomyelia. Spine 13:737-741, 1988

19. Klekamp J, Batzdorf U, Samii M, et al: The surgical treatment of Chiari I malformation. Acta Neurochir 138:788-801, 1996
20. Li KC, Chui MC: Conventional and CT metrizamide myelography in Arnold-Chiari I malformation and syringomyelia. AJNR 8:11-17, 1987

21. Milhorat TH, Chou MW, Trinidad EM, et al: Chiari I malformation redefined: clinical and radiographic findings for 364 symptomatic patients. Neurosurgery 44:1005-1017, 1999

22. Milhorat TH, Nakamura S, Heger I, et al: Ultrastructural evidence of sink function of central canal of spinal cord as demonstrated by clearance of horseradish peroxidase. Electron Microsc Soc Am Proc 50:700-701, 1992

23. Milhorat TH, Nobandegani F, Miller JI, et al: Noncommunicating syringomyelia following occlusion of the central canal in rats. Experimental model and histological findings. J Neurosurg 78:274-279, 1993

24. Nitz WR, Bradley WG Jr, Watanabe AS, et al: Flow dynamics of cerebrospinal fluid: assessment with phase-control velocity MR imaging performed with retrospective cardiac gating. Radiology 183:395-405, 1992

25. Njemanze PC, Beck OJ: MR-gated intracranial CSF dynamics: evaluation of CSF pulsatile flow. AJNR 10:77-80, 1989

26. Ohara S, Nagai H, Matsumoto T, et al: MR imaging of CSF pulsatory flow and its relation to intracranial pressure. J Neurosurg 69:675-682, 1988

27. Oldfield EH, Muraszko K, Shawker TH, et al: Pathophysiology of syringomyelia associated with Chiari I malformation of the cerebellar tonsils. Implications for diagnosis and treatment. J Neurosurg 80:3-15, 1994

28. Quencer RM, Post MJ, Hinks RS: Cine MR in the evaluation of normal and abnormal CSF flow: intracranial and intraspinal studies. Neuroradiology 32:371-391, 1990

29. Rennels ML, Gregory TF, Blaumanis OR, et al: Evidence of a 'paravascular' fluid circulation in the mammalian central nervous system, provided by the rapid distribution of tracer protein throughout the brain from the subarachnoid space. Brain Res 326:47-63, 1985

30. Resjo IM, Harwood-Nash DC, Fitz CR, et al: Computed tomographic metrizamide myelography in syringohydromyelia. Radiology 131:405-407, 1979

31. Schellinger D, LeBihan D, Rajan SS, et al: MR of slow CSF flow in the spine. AJNR 13:1393-1403, 1992

32. Sherman JL, Citrin CM, Gangarosa RE, et al: The MR appearance of CSF pulsation in the spinal canal. AJNR 7:879-884, 1986

33. Stoodley MA, Gutschmidt B, Jones NR: Cerebrospinal fluid flow in an animal model of noncommunicating syringomyelia. Neurosurgery 44:1065-1076, 1999

34. Terae S, Miyasaka K, Abe S, et al: Increased pulsatile movement of the hindbrain in syringomyelia associated with the Chiari malformation: cine-MRI with presaturation bolus tracking. Neuroradiology 36:125-129, 1994

35. Wachi A, Kudo S, Sato K: Characteristics of cerebrospinal fluid circulation in infants as detected with MR velocity imaging. Childs Nerv Syst 11:227-230, 1995

36. Williams B: Pathogenesis of syringomyelia, in Batzdorf U (ed): Syringomyelia: Current Concepts in Diagnosis and Treatment. Baltimore: Williams \& Wilkins, 1991, pp 59-90

37. Wolpert SM, Bhadelia RA, Bogdan AR, et al: Chiari I malformations: assessment with phase-contrast velocity MR. AJNR 15:299-1308, 1994

Manuscript received January 26, 2000.

Accepted in final form February 9, 2000.

Address reprint requests to: Giampietro Pinna, M.D., Department of Neurosurgery, University Hospital, Piazzale Stefani 1, 37126 Verona, Italy. email: neurochirurgia.prima@mail.azosp.vr.it. 